\title{
ĐÁNH GIÁ KHẢ NĂNG NHIỄM LISTERIA MONOCYTOGENES, STAPHYLOCOCCUS AUREUS VÀ SALMONELLA SPP. TRONG CÁC MẤU SŨA THU THẬP TẠI GIA LÂM VÀ BA Vì, HÀ NộI ĐẦU NĂM 2019
}

\author{
Nguyễn Thị Minh Huyền ${ }^{1^{*}}$, Trần Thị Hoa ${ }^{1}$, Ninh Thị Tuyết Lan ${ }^{1}$, Trần Thị Hiền ${ }^{2}$ \\ ${ }^{1}$ Viện Công nghệ sinh học, Viện Hàn lâm Khoa học và Công nghệ Việt Nam \\ ${ }^{2}$ Khoa Sinh hoc, Đại học Khoa học Tự nhiên, Đại học Quốc gia Hà Nội
}

(Ngày đến tòa soạn: 30/6/2019; Ngày sủa bài sau phản biện: 24/11/2019;

Ngày chấp nhận đăng: 30/11/2019)

\section{Tóm tắt}

Sữa và các sản phẩm sữa từ các hộ chăn nuôi bò sữa xung quanh Hà Nội đã góp phần không nhỏ vào sản lượng sữa được tiêu thụ tại Hà Nội. Việc sử dụng sữa tươi hay sữa thanh trùng đã trở nên khá thường xuyên trong sinh hoạt hàng ngày của người dân. Sữa tươi được bày bán rất nhiều tại một số các cửa hàng trên dọc các trục đường ven đô đặc biệt là ở vùng Xuân Mai, Ba Vì, Hà Nội hay Phù Đổng, Gia Lâm, Hà Nội. Các loại sữa này phần lớn đã được thanh trùng và đóng chai. Hiện nay chưa có nghiên cứu nào đánh giá về khả năng nhiễm các loại vi khuẩn có thể gây ngộ độc thực phẩm trong sữa và các sản phẩm sữa này để đánh giá sự an toàn khi tiêu thụ. Trong nghiên cứu của chúng tôi, một số mẫu sữa đã thanh trùng và sữa chưa thanh trùng được thu thập để kiểm tra sự có mặt của một số vi khuẩn gây ngộ độc thực phẩm như Listeria monocytogenes, Staphylococcus aureus, Salmonella spp. bằng phương pháp PCR. Đây là một phương pháp kiểm tra nhanh và chính xác do có khả năng nhân bản gene đặc hiệu riêng cho từng vi khuẩn cần nhận biết. Trong 49 mẫu thu thập, có 23 mẫu sữa chưa thanh trùng, 12 mẫu sữa đã thanh trùng và 14 mẫu sữa chua. Kết quả cho thấy có 01 mẫu sữa dê đã thanh trùng có khả năng nhiễm vi khuẩn Staphylococcus aureus và 01 mẫu sữa tươi chưa thanh trùng có khả năng nhiễm khuẩn Listeria monocytogenes. Tất cả các mẫu sữa và sữa chua đều âm tính với Salmonella spp. Các mẫu nhiễm khuẩn này đã được khẳng định bằng cách đọc trình tự gene.

Tù khóa: Vi khuẩn, ngộ độc thực phẩm, sũa, nhiễm khuẩn, Hà Nội.

\section{MỎं ĐÀ̀U}

Đất nước phát triển kèm theo chất lượng cuộc sống của người dân được nâng cao hơn. So với những năm cuối của thế kỷ 20 thì bước sang thế kỷ 21 , việc chăn nuôi bò sữa và sản xuất sữa ở Việt Nam đã phát triển mạnh hơn rất nhiều. Sữa tại Việt Nam hiện nay không còn hoàn toàn là sữa bột nhập ngoại và được chế biến lại nữa mà đã có rất nhiều doanh nghiệp cũng như các hộ nông dân chăn nuôi bò sữa để cung cấp sữa tươi, tự túc được một phần của nguồn nguyên liệu. Chúng ta đã có cơ hội sử dụng các sản phẩm sữa tươi từ bò hay dê được nuôi tại Việt Nam và các sản phẩm từ sữa rất đa dạng. Theo thống kê mới nhất của Tổng cục Thống kê ngày 01/10/2018, cả nước có 294,4 ngàn con bò sữa năm 2018, tăng hơn rất nhiều so với năm 2010 là 128,6 ngàn con. Sản lượng sữa năm 2010 đạt 306,7 ngàn tấn và tăng lên 936 ngàn tấn vào 
năm 2018 [1]. Ngoài các doanh nghiệp lớn như Vinamilk, TH True Milk, Mộc Châu Milk, hiện nay sữa được rất nhiều hộ gia đình sản xuất và kinh doanh nhỏ lẻ. Những hoạt động của họ liên quan từ 5 đến $10 \%$ của sữa tươi ở các địa phương và việc bán hàng hoặc là trực tiếp cho người sử dụng hoặc là cho người bán lẻ khác, ở khu vực Hà Nội [2]. Sản phẩm của họ thường rẻ hơn so với cùng sản phẩm từ các công ty lớn bởi vì họ bớt được những bước trung gian thường làm tăng thêm giá của sản phẩm đến người tiêu dùng [3]. Mặc dù họ là các nhà sản xuất nhỏ, các sản phẩm của họ ngày càng được nhiều người biết đến. Do đó, các sản phẩm của họ cũng đóng một vai trò nhất định trong thị trường sưa và các sản phẩm sữa ở miền bắc Việt Nam. Tuy nhiên, cùng với tình hình đó thì việc kiểm soát chất lượng sữa rất quan trọng bởi sữa là sản phẩm dễ nhiễm khuẩn nếu như trong quá trình sản xuất, các dụng cụ không được tiệt trùng cẩn thận. Sự nhiễm khuẩn ở sữa và các sản phẩm sữa không chỉ từ sữa thô mà còn từ các quá trình chế biến, vận chuyển và dự trữ sữa không đúng cách $[4,5]$. Do đó, việc đánh giá chất lượng sữa và các sản phẩm từ sữa bằng cách kiểm tra khả năng nhiễm khuẩn để tránh những bệnh bùng phát là rất quan trọng. Nghiên cứu này bước đầu thiết lập một phương pháp đánh giá nhanh khả năng nhiễm một số vi khuẩn gây ngộ độc thực phẩm như Listeria monocytogenes, Staphylococcus aureus, Salmonella spp. bằng PCR. Đây là một phương pháp cho kết quả chính xác và rút ngắn thời gian hơn rất nhiều so với các phương pháp vi sinh truyền thống.

\section{VẠT LIỆU VÀ PHƯƠNG PHÁP NGHIÊN CÚUU}

\subsection{Vật liệu}

- Chủng chuẩn: chủng Salmonella spp., Vibrio cholerae O1 do Công ty Cổ phần Công nghệ vi sinh và môi trường, Hà Nội cung cấp; Chủng Staphylococcus aureus và chủng Escherichia coli Shigella được tặng bởi Bộ môn Vi sinh, Đại học Y Thái Nguyên; Chủng Listeria monocytogenes mua tại khoa Vi sinh vật, Bệnh viện Quân Y 103, Hà Đông, Hà Nội. Các chủng này đều được phân lập bởi chính các nơi trên.

- Kit tinh sạch ADN, thang chuẩn ADN $1 \mathrm{~kb}$ (Thermo scientific, Đức); hóa chất để chạy PCR (Phusa Biochem, Việt Nam); thang chuẩn Ladder 100 bp (BioFact, Korea).

Các hóa chất khác sử dụng trong nghiên cứu này như EDTA, Tris-HCl, PBS, lysozyme, acetic acid, agarose...được mua từ các hãng chuyên sản xuất uy tín trên thế giới, theo đúng chuẩn cho sinh học phân tử.

- Sữa và sữa chua được thu mua chủ yếu ở hai vùng Gia Lâm và Ba Vì, Hà Nội. Mẫu tại Ba Vì được thu mua ngẫu nhiên tại các đại lý dọc trục đường Xuân Mai, Ba Vì. Mẫu sữa chưa thanh trùng tại Gia Lâm được thu mua của các hộ chăn nuôi bò tại hai xã Phù Đổng và Dương Hà khi họ mang đến bán cho đại lý của một công ty sữa lớn tại đó. Sau khi thu, mẫu được lưu trữ trong tủ đông $-20^{\circ} \mathrm{C}$ cho đến khi được sử dụng để tách chiết $\mathrm{ADN}$.

- Thiết kế mồi cho PCR: Mồi thiết kế cho phản ứng PCR được tham khảo từ một số tài liệu nghiên cứu trong đó các tác giả đã tối ưu đặc hiệu cho các vi khuẩn Listeria monocytogenes, Salmonella spp., Staphylococcus aureus và dựa trên phần mềm online Primer 3 Plus. Trong đó mồi cho Listeria monocytogenes đặc hiệu cho gene hly $A$, là gene mã hóa cho listeriolysin $\mathrm{O}$ (LLO) có liên quan đến sự thủy phân màng không bào của vật chủ. Gene này tồn tại ở tất cả các chủng Listeria monocytogenes và cần thiết để tạo đầy đủ độc lực của nó [6]. Mồi đặc hiệu cho Salmonella spp. được thiết kế dựa trên gene sdiA, là gene mã hóa cho thụ thể tín hiệu của các chất điều hòa họ LuxR. Các protein type LuxR điều hòa các nhân tố phụ có thể đóng góp cho sự tồn tại hoặc hình thành tập đoàn trong ruột của vi khuẩn Salmonella spp. [7]. Đối với Staphylococcus aureus, mồi được thiết kế đặc hiệu cho gene $n u c$, là gene mã hóa cho nuclease ổn nhiệt của Staphylococcus aureus. Đây là một endonuclease, phân hủy cả $\mathrm{ADN}$ và $\mathrm{ARN}$ và hoạt động enzyme của nó có thể chịu được ở $100^{\circ} \mathrm{C}$ trong ít nhất $1 \mathrm{~h}$ [9]. Mồi được thiết kế đặc hiệu để 
nhận biết sự có mặt của các vi khuẩn này và được trình bày ở bảng 1 dưới đây:

Bảng 1. Các mồi sủ dụng cho phản ưng PCR

\begin{tabular}{|c|c|c|c|c|c|c|}
\hline $\begin{array}{l}\text { Gene } \\
\text { mục } \\
\text { tiêu }\end{array}$ & $\begin{array}{c}\text { Tên } \\
\text { primer }\end{array}$ & Trình tụ (5'-3') & $\begin{array}{l}T m \\
\left({ }^{\circ} \mathrm{C}\right)\end{array}$ & $\begin{array}{c}\text { Chủng vi khuẩn } \\
\text { nhận biết }\end{array}$ & $\begin{array}{c}\text { Độ dài đoạn } \\
\text { gene nhân } \\
\text { bản }\end{array}$ & $\begin{array}{c}\text { Tài liệu } \\
\text { tham khảo }\end{array}$ \\
\hline \multirow{2}{*}{ lyA } & LL4R & CGC CAC ACT TGA GAT AT & 50 & \multirow{2}{*}{$\begin{array}{c}\text { Listeria } \\
\text { monocytogenes }\end{array}$} & \multirow{2}{*}{$519 \mathrm{bp}$} & \multirow{2}{*}{ [6] } \\
\hline & LL5F & AAC CTA TCC AGG TGC TC & 52,4 & & & \\
\hline \multirow{2}{*}{ sdiA } & SdiA1 & AAT ATC GCT TCG TAC CAC & 51,6 & \multirow{2}{*}{ Salmonella spp. } & \multirow{2}{*}{$257 \mathrm{bp}$} & \multirow{2}{*}{ [7] } \\
\hline & SdiA2 & GTA GGT AAA CGA GGA GCA G & 57,3 & & & \\
\hline \multirow{2}{*}{ пис } & Stanucf & ATA GGG ATG GCT ATC AGT AA & 54,3 & \multirow{2}{*}{$\begin{array}{c}\text { Staphylococcus } \\
\text { aureus }\end{array}$} & \multirow{2}{*}{$476 \mathrm{bp}$} & \multirow{2}{*}{$\begin{array}{l}\text { Nghiên cứu } \\
\text { này và [9] }\end{array}$} \\
\hline & Stanucr & TAC CAT TTT TCC ATC AGC ATA A & 54,7 & & & \\
\hline
\end{tabular}

\subsection{Phương pháp nghiên cứu}

\subsubsection{Tách ADN tổng số của chủng chuẩn}

ADN tổng số của các chủng vi khuẩn như Listeria monocytogenes, Salmonella spp., Staphylococcus aureus và một số chủng khác nhu Vibrio cholerae O1, Escherichia coli Shigella được tách sử dụng bộ Kit Thermo Scientific GeneJET Genomic DNA Purification Kit; theo protocol của nhà sản xuất dành cho vi khuẩn gram âm (Salmonella spp., Escherichia coli Shigella, Vibrio cholerae O1) và vi khuẩn gram dương (Listeria monocytogenes và Staphylococcus aureus). Cụ thể phương pháp tách có thể được tóm tắt như sau:

- Đối với vi khuẩn Gram âm, thu tế bào trong ống ly tâm 1,5 hoặc 2 ml. Hòa lại cặn tế bào trong $180 \mu \mathrm{L}$ dung dịch Digestion, thêm $20 \mu \mathrm{L}$ dung dịch protein $\mathrm{K}$ và trộn đều. Ủ mẫu ở $56^{\circ} \mathrm{C}$ trong 30 phút. Thêm $20 \mu \mathrm{L}$ dung dịch RNase $\mathrm{A}$, vortex và ủ thêm 10 phút ở nhiệt độ phòng. Thêm $200 \mu \mathrm{L}$ dung dịch lysis vào mẫu và trộn đều. Thêm $400 \mu \mathrm{L}$ của $50 \%$ cồn tinh khiết và trộn đều. Sau đó chuyển toàn bộ dịch sang cột, ly tâm ở $6000 \mathrm{~g}$ trong 1 phút. Rửa mẫu lần lượt với $500 \mu \mathrm{L}$ Wash buffer I và Wash buffer II. Sau đó ly tâm thêm 1 phút để loại sạch cồn có thể còn trong cột. Chuyển cột sang ống mới, thêm 100 hoặc $200 \mu \mathrm{L}$ Elution buffer và ủ 2 phút ở nhiệt độ phòng. Ly tâm ở tốc độ $8000 \mathrm{~g} /$ phút trong 1 phút. Loại bỏ cột và dự trữ $\mathrm{ADN}$ ở $-20^{\circ} \mathrm{C}$ cho đến khi sử dụng. Nồng độ $\mathrm{ADN}$ được xác định bằng cách đo hấp thụ với máy nanodrop. Kết quả thu được được phần mềm tự động của máy tính ra nồng độ ADN theo ng/ $\mu \mathrm{L}$. Các mẫu $\mathrm{ADN}$ được lưu trữ trong tủ âm $20^{\circ} \mathrm{C}$ đến khi sử dụng để thực hiện các thí nghiệm tiếp theo.

- Đối với vi khuẩn gram dương, các bước tách chiết cũng được tiến hành tương tự, ngoại trừ bước ly giải tế bào. Cụ thể như sau: dung dịch ly giải tế bào cho vi khuẩn gram dương: 20 mM Tris-HCl, pH 8,0, 2 mM EDTA, 1,2\% Triton $\mathrm{x}-100$, thêm lysozyme đến nồng độ $20 \mathrm{mg} / \mathrm{mL}$ trước khi dùng. Đầu tiên, tế bào sau khi thu bằng ly tâm sẽ được ủ với $180 \mu 1$ dung dịch trên trong 30 phút ở $37^{\circ} \mathrm{C}$. Sau đó thêm $200 \mu \mathrm{L}$ dung dịch lysis, $20 \mu \mathrm{L}$ proteinase $\mathrm{K}$ và trộn đều, ủ thêm ở $56^{\circ} \mathrm{C}$ trong 30 phút. Các bước tiếp theo tiến hành như đối với vi khuẩn gram âm. Nồng độ $\mathrm{ADN}$ được xác định bằng cách đo hấp thụ với máy nanodrop và tương tự như trên, các mẫu $\mathrm{ADN}$ được lưu trữ trong tủ âm $20^{\circ} \mathrm{C}$ đến khi sử dụng để thực hiện các thí nghiệm tiếp theo.

\subsubsection{Tách ADN tổng số tù̀ sũa và sũa chua}

Do ADN từ sữa có nhiều loại (vi khuẩn có thể có trong sữa, $\mathrm{ADN}$ còn lại từ vật nuôi cho sữa...), ngoài ra trong sữa còn rất nhiều các thành phần protein khác nên việc tách $\mathrm{ADN}$ phức 
tạp hơn. Trong nghiên cứu này, chúng tôi vẫn sử dụng kit để tách ADN. Tuy nhiên các bước chuẩn bị trước khi tách $\mathrm{ADN}$ được thực hiện như sau: $2 \mathrm{ml}$ sữa được ly tâm trong 10 phút ở $10000 \mathrm{~g}, 3$ phút ở $12000 \mathrm{~g}$, và 5 phút ở $5000 \mathrm{~g}$. Phần lớp chất béo và dịch nổi được loại bỏ. Tùy thuộc vào lượng chất béo còn lại trong ống mà các bước rửa được tiến hành như sau: thêm $500 \mu \mathrm{L}$ của dung dịch $5 \mathrm{xSSC}(0,75 \mathrm{M} \mathrm{NaCl}, 0,075 \mathrm{M}$ trisodium citrate dihydrate) và $75 \mu \mathrm{L}$ của dung dịch $40 \%$ trisodium citrate dehydrate, trộn đều, ủ ở nhiệt độ phòng 5 phút, ly tâm ở tốc độ tối đa trong 2 phút và loại bỏ dịch nổi. Lặp lại bước rửa đến khi loại được phần lớn lớp chất béo trong sữa. Phần cặn được sử dụng để tách $\mathrm{ADN}$ tổng số sử dụng protocol cho vi khuẩn gram dương của bộ kit Thermo Scientific GeneJET Genomic DNA Purification Kit. Nồng độ ADN được xác định bằng cách đo hấp thụ với máy nanodrop.

Với sữa chua, việc tách chiết cũng được thực hiện như với sữa tươi ngoại trừ bước ban đầu như sau: Cân 1 gram sữa chua cho vào ống $2 \mathrm{ml}$. Thêm $100 \mu \mathrm{L}$ của $0,4 \mathrm{M} \mathrm{NaOH}+75 \mu \mathrm{L}$ của $40 \%$ trisodium citrate dehydrate, vortex, ủ ở nhiệt độ phòng trong 5 phút và ly tâm tốc độ tối đa trong 3 phút. Loại bỏ dịch nổi và tiến hành rửa và tách $\mathrm{ADN}$ như với các mẫu sữa ở trên. Nồng độ $\mathrm{ADN}$ được xác định bằng cách đo hấp thụ với máy nanodrop. Kết quả thu được được phần mềm tự động của máy tính ra nồng độ $\mathrm{ADN}$ theo $\mathrm{ng} / \mu \mathrm{L}$. Các mẫu $\mathrm{ADN}$ được lưu trữ trong tủ âm $20^{\circ} \mathrm{C}$ đến khi sử dụng để thực hiện các thí nghiệm tiếp theo.

\subsubsection{Chay PCR và kiểm tra kết quả}

Hỗn hợp phản ứng PCR được trộn như sau: $1 \times$ PCR buffer $22,5 \mu \mathrm{L}, 10$ pmol primer $0,5 \mu \mathrm{L}$ mỗi loại, $\mathrm{ADN}$ khuôn $0,5 \mu \mathrm{L}$, nước vừa đủ $25 \mu \mathrm{L}$ (EZ PCR mix, Phusa Biochem). Phản ứng PCR nhân bản gene đặc hiệu để nhận biết vi khuẩn được thực hiện trên máy chu trình nhiệt Applied Bioscience Veriti 96 giếng theo chương trình như sau: 1. Tiền biến tính $95^{\circ} \mathrm{C}$ trong 3 phút; 2. Biến tính $95^{\circ} \mathrm{C}$ trong 30 giây; 3 . Gắn mồi ở $52^{\circ} \mathrm{C} \sim 57^{\circ} \mathrm{C}$ trong 30 giây đến 50 giây tùy thuộc vào độ dài đoạn sản phẩm PCR; 4 . Kéo dài chuỗi ở $72^{\circ} \mathrm{C}$ trong 40 giây; lặp lại các bước 2 đến bước 4 cho 30 đến 35 chu kỳ; và bước kéo dài chuỗi cuối cùng là $72^{\circ} \mathrm{C}$ trong 5 phút. Sản phẩm của phản ứng PCR được kiểm tra bằng phương pháp điện di trên thạch agarose $1 \%$ ở điện thế $100 \mathrm{~V}$ trong thời gian 30 phút và kiểm tra kết quả bằng cách soi với đèn UV visualizer.

\subsubsection{Khảo sát xây dựng quy trình phát hiện các vi khuẩn bằng phản ứng $P C R$}

\subsubsection{Khảo sát khả năng bắt cặp đặc hiệu của mồi}

Khả năng bắt cặp đặc hiệu của từng mồi thiết kế cho từng loại vi khuẩn được đánh giá bằng cách chạy $\mathrm{PCR}$ của từng cặp mồi với khuôn $\mathrm{ADN}$ của các loại vi khuẩn làm đối chứng kiểm định. Chẳng hạn như, khi kiểm tra độ đặc hiệu của mồi dùng để phát hiện vi khuẩn Listeria monocytogenes, chúng tôi chạy $\mathrm{PCR}$ đồng thời của cặp mồi này với các khuôn $\mathrm{ADN}$ của các chủng vi khuẩn khác như Salmonella spp., Staphylococcus aureus, Vibrio cholerae O1, E. coli, Shigella và tương tự như vậy đối với mồi đặc hiệu cho các vi khuẩn Salmonella spp., Staphylococcus aureus trong nghiên cứu này. Kết quả điện di sản phẩm PCR không xuất hiện các vạch dương tính khi sử dụng khuôn $\mathrm{ADN}$ của các vi khuẩn đối chứng kiểm định sẽ đánh giá được mồi chỉ đặc hiệu cho từng vi khuẩn nhận biết đã thiết kế.

2.2.4.2. Khảo sát nồng độ ADN tối thiểu của các phản ứng PCR phát hiện Salmonella spp., Staphylococcus aureus và Listeria monocytogenes

Sau khi tách chiết, nồng độ ADN ban đầu của các vi khuẩn Salmonella spp., Staphylococcus aureus và Listeria monocytogenes lần lượt là: $77 \mathrm{ng} / \mu \mathrm{L}, 39 \mathrm{ng} / \mu \mathrm{L}$ và $68 \mathrm{ng} / \mu \mathrm{L}$. ADN ban đầu được pha loãng giảm dần 10 lần theo thứ tự các nồng độ từ $10^{-1}$ đến $10^{-9}$ và các nồng độ $\mathrm{ADN}$ sau khi pha loãng này được sử dụng để làm khuôn cho các phản ứng PCR với các cặp mồi đặc hiệu riêng cho từng khuôn. Sản phẩm PCR được điện di kiểm tra trên gel agarose $1 \%$ ở $100 \mathrm{~V}$ trong thời gian 30 phút. Nồng độ $\mathrm{ADN}$ tối thiểu cho phép phản ứng $\mathrm{PCR}$ phát hiện chủng vi 
khuẩn được đánh giá ở nồng độ $\mathrm{ADN}$ thấp nhất vẫn xuất hiện vạch $\mathrm{ADN}$ dương tính trên bản gel điện di agarose $1 \%$.

\section{KẾT QUẢ VÀ THẢO LUẬN}

\section{1. Đánh giá khả năng bắt cặp đặc hiệu của các cặp mồi}

Sản phẩm PCR xuất hiện ở giếng số 5 (hình $1 \mathrm{~A}$ và hình $1 \mathrm{C}$ ), giếng số 1 (hình $1 \mathrm{~B}$ ) với một băng rõ nét có kích thước tương ứng với sản phẩm PCR dự kiến (hình 1A: 476 bp cho Staphylococcus aureus, hình 1B: 257 bp cho Salmonella spp. và hình 1C: 519 bp cho Listeria monocytogenes). Đối với các giếng còn lại ở các hình $1 \mathrm{~A}, 1 \mathrm{~B}$, và $1 \mathrm{C}$ khuôn $\mathrm{ADN}$ được sử dụng là các khuôn không đặc hiệu cho các cặp mồi Stanucf và Stanucr (hình $1 \mathrm{~A}$ ); SdiA1 và SdiA2 (hình $1 \mathrm{~B}$ ); và LL4R và $\mathrm{LL} 5 \mathrm{~F}$ (hình $1 \mathrm{C}$ ) do đó không có băng sáng nào xuất hiện ở các giếng này. Kết quả thử nghiệm cho thấy cặp mồi Stanucf/r đặc hiệu nhận biết đối với khuôn ADN của vi khuẩn Staphylococcus aureus, cặp mồi SdiA1/2 đặc hiệu cho khuôn DNA của vi khuẩn Salmonella spp. và cặp mồi LL4R/5F đặc hiệu cho khuôn $\mathrm{ADN}$ của vi khuẩn Listeria monocytogenes. Kích thước sản phẩm PCR dự kiến và kích thước thực tế so với thang $\mathrm{ADN}$ chuẩn trên bản điện di có hơi sai lệch do quá trình điện di có thể phụ thuộc cả vào cấu trúc 3 chiều của phân tử ADN cũng như thành phần của gel agarose chưa đồng nhất hoàn toàn ở một số vị trí.

\subsection{Khảo sát nồng độ $\mathrm{ADN}$ tối thiểu của các phản ứng PCR nhận biết vi khuẩn Listeria monocytogenes, Staphylococcus aureus và Salmonella spp.}

Nồng độ $\mathrm{ADN}$ khuôn của các phản ứng $\mathrm{PCR}$ giảm dần thì cường độ sáng của vạch $\mathrm{ADN}$ trên ảnh điện di cũng giảm dần (hình 2). Đối với Staphylococcus aureus nồng độ ADN giảm đến $39 \times 10^{-4} \mathrm{ng} / \mu \mathrm{L}$ thì còn một băng mờ và không rõ nét, và đến $39 \times 10^{-5} \mathrm{ng} / \mu \mathrm{L}$ thì không còn thấy xuất hiện băng nào nữa (giếng số 5 và 6 trên hình $2 \mathrm{~A}$ ). Như vậy, nồng độ $\mathrm{ADN}$ khuôn tối thiểu của vi khuẩn Staphylococcus aureus trong thí nghiệm này có thể nhận biết bằng phản ứng PCR là $39 \times 10^{-4} \mathrm{ng} / \mu \mathrm{L}$ (hay $3,9 \mathrm{pg} / \mu \mathrm{L}$ ). Dưới nồng độ này lượng $\mathrm{ADN}$ không đủ để tạo ra sản phẩm PCR có thể quan sát được trên bản gel điện di. Theo nghiên cứu của Gandra et al. [13], nồng độ ADN của Staphylococcus aureus được nhận biết bởi PCR là khoảng 1,63 $\mathrm{pg} / \mu \mathrm{L}$. Như vậy độ nhạy của phản ứng PCR của Gandra et al. hiệu quả cao hơn so với nghiên cứu này. Điều này có thể do độ tinh khiết của $\mathrm{ADN}$ trong trong phản ứng $\mathrm{PCR}$ của nghiên cứu này chưa cao.
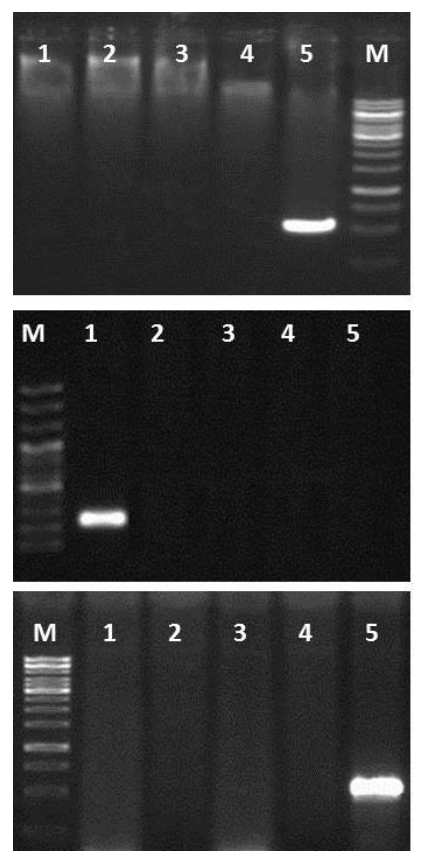

A

1, E.coli shigella;

2, V. cholerae 01;

3, Salmonella spp;

4, Listeria monocytogenes;

5, Staphylococcus aureus;

$\mathrm{M}: 1 \mathrm{~kb}$ ladder marker

\section{B}

M: 100 bp Plus ladder marker

1, Salmonella spp;

2, E.coli shigella;

3, V. cholerae 01;

4, Listeria monocytogenes;

5, Staphylococcus aureus

\section{C}

$\mathrm{M}: 1 \mathrm{~kb}$ ladder marker

1, E.coli shigella;

2, V. cholerae 01;

3, Salmonella spp;

4, Staphylococcus aureus;

5, Listeria monocytogenes

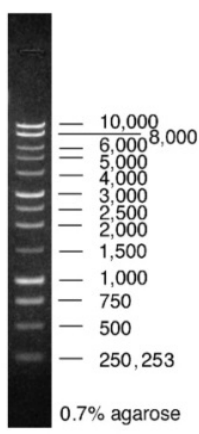

Hình 1. Đánh giá khả năng bằt cặp đặc hiệu của các cặp mồi thiết kế để nhận biêt Staphylococcus aureus, Salmonella spp. và Listeria monocytogenes.

ADN của các chủng vi khuẩn được tách chiết và sử dụng làm khuôn cho phản ưng PCR với tùng cặp mồi.

Hình A. Kết quả PCR sủ dụng cặp mồi Stanucf và Stanucr vói các mẫu ADN.

Hình B. Kết quả PCR sư dụng cặp mồi SdiA1 và SdiA2 với các mẫu $A D N$. Hinh C. Kết quả PCR sư dụng cặp mồi $L L 4 R$ và $L L 5 F$ với các mẫu ADN. M: $1 K b$ DNA ladder hoặc 100bp (hình bên phải). 
Đối với phản ứng PCR trong đó $\mathrm{ADN}$ khuôn từ Salmonella spp., nồng độ $\mathrm{ADN}$ mà ở đó vẫn xuất hiện một băng có thể nhìn thấy bằng mắt thường qua UV visualizer là ở độ pha loãng $77 \times 10^{-5} \mathrm{ng} / \mu \mathrm{L}(0,77 \mathrm{pg} / \mu \mathrm{L}$, giếng số 6 trên hình $2 \mathrm{~B})$. Ở nồng độ pha loãng hơn thì không quan sát được sự xuất hiện băng $\mathrm{ADN}$. Do đó, nồng độ pha loãng tối thiểu của Salmonella spp. trong phản ứng $25 \mu \mathrm{L}$ trong thí nghiệm này là $0,77 \mathrm{pg} / \mu \mathrm{L}$ (hình $2 \mathrm{~B}$ ). Công bố của Moganedi et at. [14] với độ nhạy của phản ứng PCR nhận biết vi khuẩn Salmonella spp. là $0,3 \mathrm{pg} / \mu \mathrm{L}$, trong khi với nhóm Radhika là $5 \mathrm{pg} / \mu \mathrm{L}$ [15] hay Kumar et al. là 3 pg/ $\mu \mathrm{L}$ [16]. Như vậy, trong trường hợp nhận biết Salmonella spp. kết quả của chúng tôi nằm ở mức trung bình so với các công bố của các nhóm nghiên cứu này. So với hai nhóm sau thì thậm chí kết quả của chúng tôi tốt hơn $[15,16]$.

Trong trường hợp sử dụng cặp mồi LL4R/LL5F dùng để nhận biết vi khuẩn Listeria monocytogenes, nồng độ $\mathrm{ADN}$ mà ở đó vẫn xuất hiện băng có thể quan sát được trên bản gel agarose $1 \%$ là $68 \times 10^{-5} \mathrm{ng} / \mu \mathrm{L}(0,68 \mathrm{pg} / \mu \mathrm{L}$, giếng số 6 trên hình $2 \mathrm{C})$. Ở nồng độ $68 \times 10^{-6} \mathrm{ng} / \mu \mathrm{L}$ (giếng số 7 hình $2 \mathrm{C}$ ) không xuất hiện băng nào có thể quan sát được bằng mắt thường. Như vậy ngưỡng phát hiện $\mathrm{ADN}$ khuôn tối thiểu của cặp mồi LL4R/LL5F là $0,68 \mathrm{pg} / \mu \mathrm{L}$ trong phản ứng $25 \mu \mathrm{L}$. Với công bố của nhóm Wang et al. [12], nồng độ $\mathrm{ADN}$ sau khi PCR mà tại đó vẫn xuất hiện băng sáng trên gel agarose là $25 \mathrm{pg} /$ phản ứng $20 \mu \mathrm{L}$. Như vậy thì trong thí nghiệm này, độ nhạy của phản ứng PCR của chúng tôi là vượt trội hơn so với công bố trên.
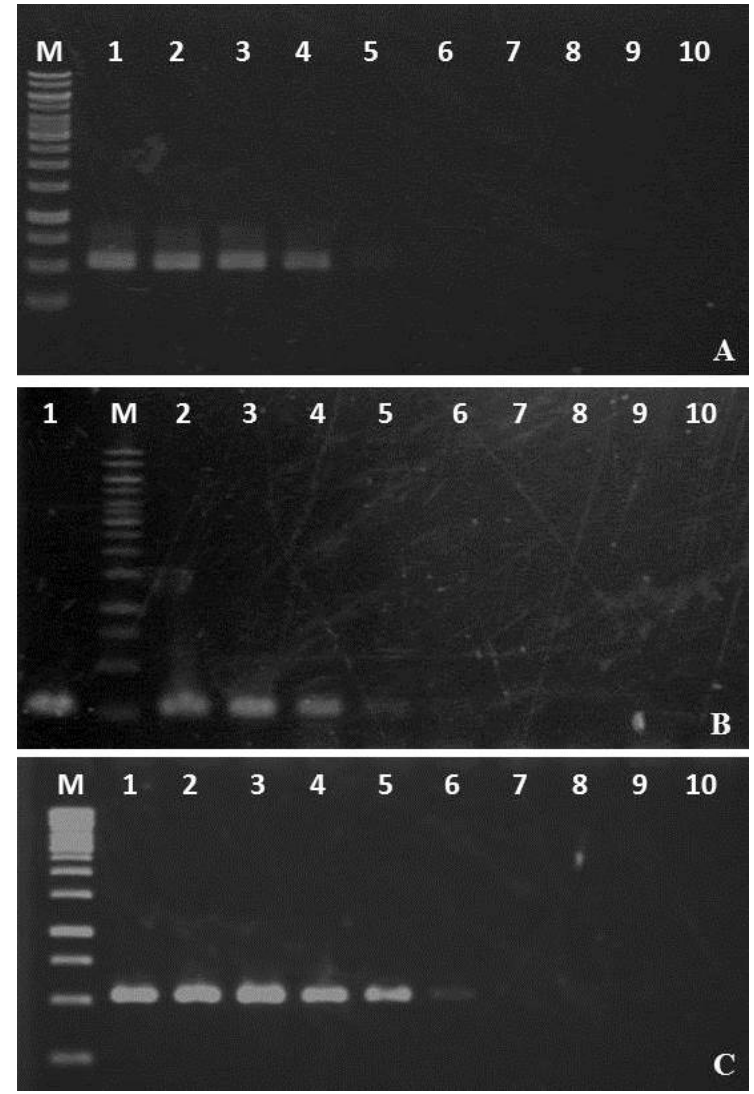

Hình 2. Khảo sát nồng độ ADN tối thiểu các phản úng PCR nhận biết vi khuẩn Listeria monocytogenes, Staphylococcus aureus và Salmonella spp.

ADN của các chủng vi khuẩn được pha loãng theo loạt giảm dần 10 lần tì̀ $10^{-1}$ đến $10^{-9}$ và sủ dụng làm khuôn cho phản úng $P C R$ vói tùng cặp mồi đặc trung.

Hình A. Kết quả PCR sủ dụng cặp mồi Stanucf và Stanucr với các mẫu ADN pha loãng của vi khuẩn Staphylococcus aureus.

Hình B. Kết quả PCR sủ dụng cặp mồi SdiAl và SdiA2 với các mẫu ADN pha loãng của vi khuẩn Salmonella spp.

Hinh C. Kết quả PCR sư dung cặp mồi LL4R và $L L 5 F$ với các mẫu $A D N$ pha loãng của vi khuẩn Listeria monocytogenes. $M$ : $1 \mathrm{~Kb}$ DNA ladder. Thứ tư mẫu tù 1 dến 10 theo thư tụ lần luợt nhu sau: 1, ADN không pha loãng, tì̀ $2^{-10}$, nồng độ pha loãng lần lượt tù̀ $10^{-1}$ đến $10^{-9}$

\subsection{Nhận biết vi khuẩn Listeria monocytogenes trong sữa và sữa chua}

Listeria monocytogenes là vi khuẩn có thể gây tử vong cho người nếu như nhiễm phải, đặc biệt là ở trẻ sơ sinh, phụ nữ mang thai, người già, và người bị suy giảm miễn dịch. Thế giới đã ghi nhận có những trận dịch lớn tại Mỹ hoặc Pháp làm chết nhiều người do ăn phải thức ăn bị nhiễm vi khuẩn này (8). Sữa chưa tiệt trùng hay các sản phẩm làm từ sữa chưa tiệt trùng cũng là một nguồn có khả năng nhiễm khuẩn gây bệnh. Với các kết quả tối ưu như trên, chúng tôi đã 
sử dụng khuôn $\mathrm{ADN}$ là $\mathrm{ADN}$ tổng số được tách từ các mẫu sữa và sữa chua để chạy PCR với mồi đặc hiệu của vi khuẩn Listeria monocytogenes.

Trong số 49 mẫu sữa và sữa chua thu thập được, chỉ có 01 mẫu có xuất hiện băng sáng có kích thước giống với kích thước của đối chứng dương (ADN của chính vi khuẩn Listeria monocytogenes được dùng làm khuôn) ở vị trí thứ 16 trên hình số 3. Mẫu này là mẫu sữa tươi chưa thanh trùng thu thập được tại xã Dương Hà, Gia Lâm, Hà Nội. Các mẫu sữa còn lại không xuất hiện băng sáng nào trên bản gel agarose (còn một số hình bản gel khác không được thể hiện tại đây). Mẫu $\mathrm{ADN}$ trên cũng đã được gửi đi đọc trình tự và kết quả khẳng định đó là vi khuẩn Listeria monocytogenes (Bảng 2). Như vậy, khả năng bị ngộ độc thực phẩm khi uống sữa này có thể xảy ra nếu như sữa không được tiệt trùng hoặc thanh trùng trước khi dùng. May mắn là phần lớn sữa tươi sản xuất tại Gia Lâm được thu mua bởi một công ty sữa lớn tại Việt Nam và sẽ được xử lý trên dây chuyền thiết bị có kiểm soát chất lượng tốt. Nguy cơ này có khả năng xảy ra nếu sữa được bán trực tiếp cho người dân và như vậy cần phổ biến mọi người nên đun nóng lại sữa trước khi sử dụng.

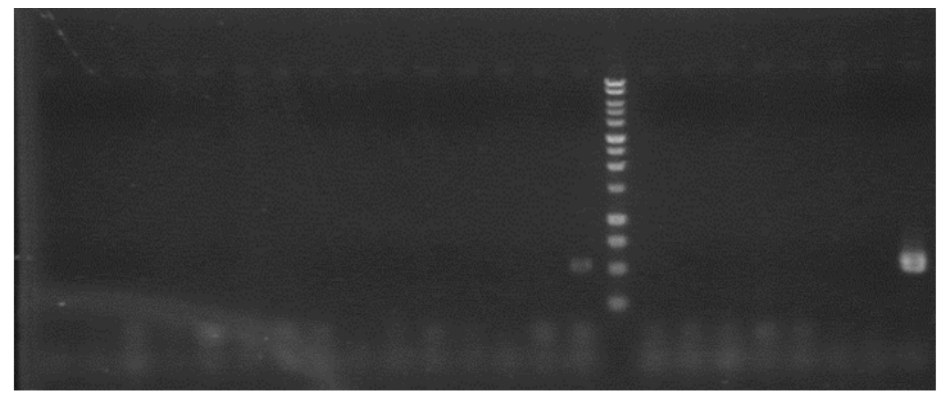

Hình 3. Kết quả PCR của các mẫu sũa với mồi đặc hiệu cho Listeria monocytogenes

Tù̀ 1 đến 24, các mẫu sũa đã thu thập; 25, đối chứng duơng (Listeria monocytogenes). Chỉ mẫu 16 xuất hiện băng tuoong tụ dối chưng duơng. $M: 1 K b$ DNA ladder

12345678910111213141516 M 1819202122232425

Bảng 2. Trình tụ ADN mẫu số 16 (hình 3) được BLAST trên NCBI Listeria monocytogenes strain N12-0935 chromosome, complete genome Sequence ID: CP038642.1Length: 2986680Number of Matches: 1 Range 1: 2269036 to 2269523 GenBankGraphics Next MatchPrevious Match

\begin{tabular}{|c|c|c|c|c|c|}
\hline \multirow{2}{*}{\multicolumn{2}{|c|}{ Score }} & \multicolumn{4}{|c|}{ Alignment statistics for match \#1 } \\
\hline & & Expect & Identities & Gaps & Strand \\
\hline \multicolumn{2}{|c|}{878 bits $(475)$} & 0.0 & $484 / 488(99 \%)$ & $2 / 488(0 \%)$ & Plus/Minus \\
\hline \multirow[t]{2}{*}{ Query } & 2 & \multicolumn{3}{|c|}{ TGCATTC-CTCCAGGCGCTTGCA-CTGCTCTTTAGTAACAGCTTTGCCGAAAAATCTGGA } & 59 \\
\hline & & \multicolumn{3}{|c|}{ 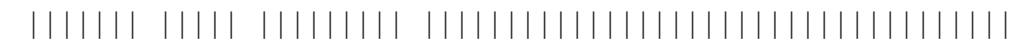 } & \\
\hline Sbjet & 2269523 & \multicolumn{3}{|c|}{ TGCATTCACTCCAAGCGCTTGCAACTGCTCTTTAGTAACAGCTTTGCCGAAAAATCTGGA } & 2269464 \\
\hline Query & 60 & \multicolumn{3}{|c|}{ AGGTCTTGTATGTTCATTAACATTCACGTTATAGTAAATTTGTTTAAAACTAATGACTTC } & 119 \\
\hline & & \multicolumn{3}{|c|}{|||||||||||||||||||||||||||||||||||||||||||||||||||||||||| $\mid$} & \\
\hline Sbjet & 2269463 & \multicolumn{3}{|c|}{ AGGTCTTGTAGGTTCATTAACATTCACGTTATAGTAAATTTGTTTAAAACTAATGACTTC } & 2269404 \\
\hline Query & 120 & \multirow{2}{*}{\multicolumn{3}{|c|}{ 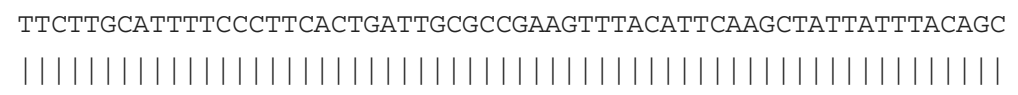 }} & 179 \\
\hline & & & & & \\
\hline bjet & 2269403 & \multicolumn{3}{|c|}{ TTCTTGCATTTTCCCTTCACTGATTGCGCCGAAGTTTACATTCAAGCTATTATTTACAGC } & 2269344 \\
\hline uery & 180 & \multirow{2}{*}{\multicolumn{3}{|c|}{ 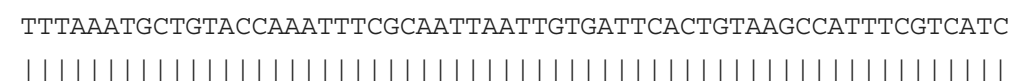 }} & 239 \\
\hline & & & & & \\
\hline$C$ & 2269343 & \multicolumn{3}{|c|}{ TTTAAATGCTGTACCAAATTTCGCAATTAATTGTGATTCACTGTAAGCCATTTCGTCATC } & 226928 \\
\hline
\end{tabular}




\begin{tabular}{|c|c|c|c|}
\hline Query & 240 & АТААТСААТTTTTGCACTTACATTTGGATAAGCTTGAGCATATTTTTCATTCСАTСTTTС & 299 \\
\hline & & |||||||||||||||||||||||||||||||||||||||||||||||||||| $\mid$ & \\
\hline Sbjet & 2269283 & 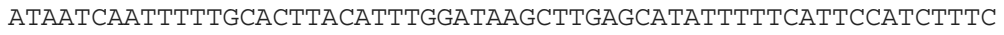 & 2269224 \\
\hline Query & 300 & САСTAATGTATTTACTGCGTTGTTAACGTTTGATTTAGTGGCATTTTTTACAACGATTTT & 359 \\
\hline & & 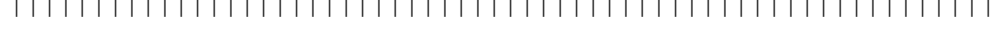 & \\
\hline Sbjet & 2269223 & САСTAATGTATTTACTGCGTTGTTAACGTTTGATTTAGTGGCATTTTTTACAACGATTTT & 2269164 \\
\hline Query & 360 & АTTGTCTTGATTAGTCATACCTGGCAAATCAATGCTGAGTGTTAATGAATCACGTTTTAC & 419 \\
\hline & & |||||||||||||||||||||||||||||||||||||||||||||||||||| $\mid$ & \\
\hline Sbjet & 2269163 & АTTGTCTTGATTAGTCATACCTGGCAAATCAATGCTGAGTGTTAATGAATCACGTTTTAC & 2269104 \\
\hline Query & 420 & AGGGAGAACATCTGGTTGATTTTCTACTAATTCCGAATTCGCTTTTACGAGAGCACCTGG & 479 \\
\hline & & |||||||||||||||||||||||||||||||||||||||||||||||||| & \\
\hline Sbjet & 2269103 & AGGGAGAACATCTGGTTGATTTTСTACTAАTTCCGAАTTCGCTTTTACGAGAGCACCTGG & 2269044 \\
\hline Query & 480 & ATAGGTTA 487 & \\
\hline Sbjet & 2269043 & ATAGGTTA 2269036 & \\
\hline
\end{tabular}

\subsection{Nhận biết vi khuẩn Staphylococcus aureus trong sữa và sữa chua}

Staphylococcus aureus hay tụ cầu vàng có thể gây nhiễm khuẩn tụ cầu. Nhiễm khuẩn tụ cầu có thể gây nguy hiểm đến tính mạng nếu vi khuẩn tụ cầu lưu thông trong máu. Khi ăn phải thức ăn nhiễm khuẩn này, người bệnh bị nôn mửa dữ dội và có thể bị sốt. Khả năng gây bệnh của vi khuẩn là do nó có thể sinh độc tố enterotoxin, là một protein bền nhiệt. Sữa và các sản phẩm từ sữa cũng chứa nguy cơ gây bệnh nếu như động vật cho sữa nhiễm bệnh hoặc quá trình chế biến sữa không an toàn. Trong nghiên cứu này, Staphylococcus aureus cũng là đối tượng để kiểm tra khả năng nhiễm của nó trong các mẫu sữa và sữa chua đã thu thập được.

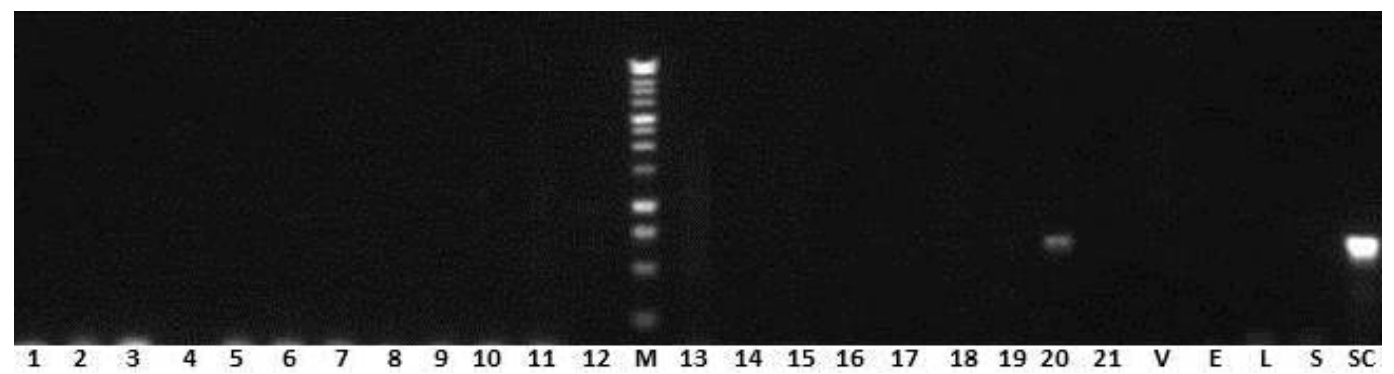

Hình 4. Kết quả PCR với mồi đặc hiệu cho Staphylococcus aureus

Tù 1 đến 21, các mẫu sũa đã thu thập; V. cholerae O1; E.coli; Shigella; Listeria monocytogenes;

Salmonella spp.; Staphylococcus aureus; M: 1 Kb DNA ladder của Thermo Scientific

Trong các mẫu sữa và sữa chua thu thập, chúng tôi phát hiện 01 mẫu có khả năng nhiễm khuẩn Staphylococcus aureus (giếng 20 trên hình 4). Mẫu này là mẫu sữa dê đã được thanh trùng của một trang trại nhỏ trên vùng $B a$ Vì, Hà Nội. Mẫu $\mathrm{ADN}$ này đã được khẳng định là $\mathrm{ADN}$ của vi khuẩn Staphylococcus aureus bằng cách đọc trình tự (Bảng 3 ). Việc nhiễm khuẩn Staphylococcus aureus này có thể là do quá trình chế biến đóng chai sữa không hoàn toàn đảm bảo vô trùng. Như vậy, nguy cơ bị ngộ độc thực phẩm khi tiêu thụ sữa này là hoàn toàn có thể xảy ra. Trong những năm gần đây, tình hình ngộ độc do uống sữa xảy ra cũng khá nhiều. Trong các nguyên nhân ngộ độc đã tìm được thì có cả sữa nhiễm vi khuẩn Staphylococcus aureus như: vụ ngộ độc sữa tại hai Trường Tiểu học ở Hậu Giang vào năm 2017 (10). Ngoài ra, riêng đến 
hết tháng 10/2018, tụ cầu vàng được coi là "thủ phạm số 1 " gây nên các vụ ngộ độc tập thể trên cả nước (11). Tóm lại, mặc dù sữa đã thanh trùng nhưng vẫn có khả năng nhiễm lại các loại vi khuẩn gây bệnh nếu như quá trình sau khi thanh trùng không đảm bảo; cần phải có các biện pháp kiểm soát nhằm đảm bảo an toàn cho người sử dụng sữa và các sản phẩm sữa từ các hộ chế biến kinh doanh nhỏ lẻ hiện nay.

\section{Bảng 3. Trình tụ ADN mẫu số 20 (hình 4) được BLAST trên NCBI}

Staphylococcus aureus strain GD1696 chromosome, complete genome

Sequence ID: CP040233.2 Length: 2801264Number of Matches: 1

Range 1: 514573 to 515018 GenBankGraphics Next MatchPrevious Match Alignment statistics for match \#1

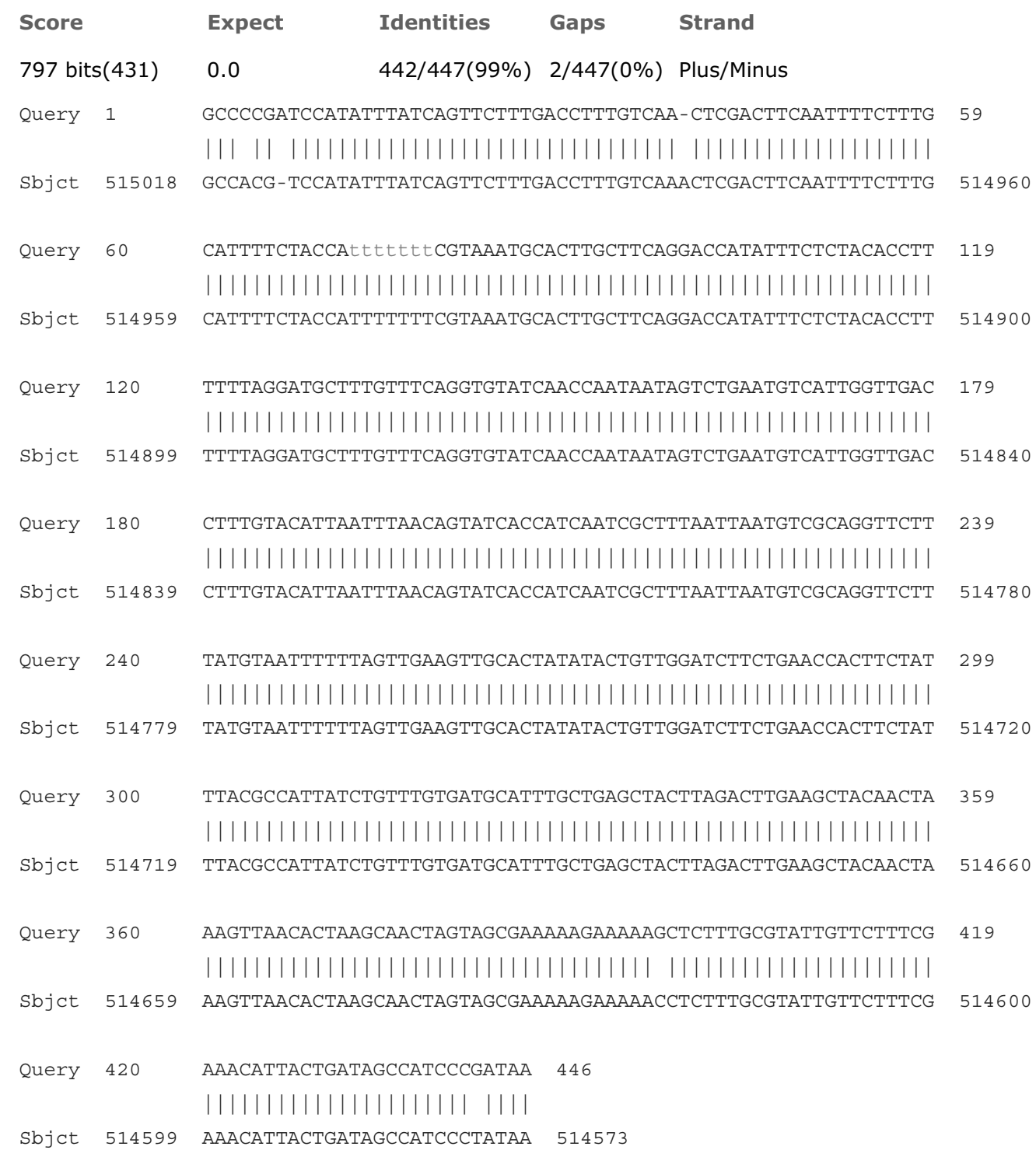

\subsection{Nhận biết vi khuẩn Salmonella spp. trong sữa và sữa chua}

Ngoài bệnh thương hàn và phó thương hàn gây nhiễm trùng máu, Salmonella spp. cũng là một loại vi khuẩn thường gây ngộ độc thực phẩm. Các triệu chứng do Salmonella spp. gây ra thường là tiêu chảy, nôn mửa và kéo dài từ 2 đến 7 ngày. Sữa chưa tiệt trùng có thể là một nguồn nhiễm khuẩn này. Tất cả các mẫu sữa và sữa chua trong nghiên cứu này đã được kiểm tra bằng 
PCR để phát hiện khả năng nhiễm khuẩn Salmonella spp. May mắn là trong tất cả các mẫu sữa và sữa chua đã thu thập, chúng tôi không phát hiện một trường hợp nào dương tính với vi khuẩn Salmonella spp. ngoại trừ đối chứng dương là DNA khuôn từ chính vi khuẩn Salmonella spp. (dữ liệu không thể hiện trong bài). Thí nghiệm này đã được lặp lại 03 lần và kết quả là đồng nhất. Như vậy, các mẫu sữa và sữa chua trong thí nghiệm này không chứa vi khuẩn Salmonella spp.

\section{KẾT LUẬN VÀ KIẾN NGH!}

Trong nghiên cứu này, chúng tôi đã thiết lập được phương pháp phát hiện nhanh vi khuẩn Staphylococcus aureus, Listeria monocytogenes và Salmonella spp. bằng kỹ thuật PCR. Kết quả cho thấy các cặp mồi đã thiết kế riêng cho từng vi khuẩn có độ đặc hiệu cao với các vi khuẩn. Nồng độ DNA tối thiểu trong phản ứng phát hiện các vi khuẩn Staphylococcus aureus, Listeria monocytogenes và Salmonella spp. lần lượt là $3,9 \mathrm{pg} / \mu \mathrm{l}, 0,68 \mathrm{pg} / \mu \mathrm{l}$ và $0,77 \mathrm{pg} / \mu \mathrm{l}$. Kết quả này cũng khá tương đồng với nhiều nghiên cứu đã công bố và đã được áp dụng để khảo sát sự có mặt của các vi khuẩn này trên các mẫu sữa và sữa chua thu thập.

Trong 49 mẫu thu thập tại các vùng gần Hà Nội đầu năm 2019, có 23 mẫu sữa chưa thanh trùng, 12 mẫu sữa đã thanh trùng và 14 mẫu sữa chua. Kết quả cho thấy có 01 mẫu sữa dê đã thanh trùng lấy tại $\mathrm{Ba}$ Vì, Hà Nội có khả năng nhiễm vi khuẩn Staphylococcus aureus và 01 mẫu sữa tươi chưa thanh trùng lấy tại Gia Lâm, Hà Nội có khả năng nhiễm khuẩn Listeria monocytogenes. Tất cả các mẫu sữa và sữa chua đều âm tính với Salmonella spp. Các mẫu nhiễm khuẩn này đã được khẳng định bằng cách đọc kết quả giải trình tự gene. Từ kết quả này ta thấy quá trình xử lý sau khi thanh trùng sữa rất quan trọng để tránh nhiễm ngược lại vào sữa và có thể nhận thấy không nên sử dụng sữa chưa thanh trùng hay chưa tiệt trùng để đảm bảo sức khỏe người tiêu dùng. Như vậy, các nhà quản lý cần đưa ra các biện pháp phải lưu ý hơn để lấy mẫu kiểm tra giám sát thường xuyên các mẫu sữa và sản phẩm của sữa để phòng, tránh việc có thể xảy ra các vụ ngộ độc tập thể từ sữa và các sản phẩm của sữa không an toàn.

\section{TÀI LIẸU THAM KHẢO}

1. Năm 2018 - Những nỗ lực của ngành Sữa Việt Nam (15/1/2019). Hiệp hội Sữa Việt Nam.

2. Otto Garcia et. al. (2006), "The Economics of Milk Production in Hanoi, Vietnam with Particular Emphasis on Small-scale Producers", FAO, PPLPI Working Paper No.33.

3. Nguyen Anh Phong, (2015), "Small holder involvement in Vinamilk supply chain, Vietnam", FAO

4. Mahendra Pal et. al. (2016), "Bacterial Contamination of Dairy Products", Beverage \& Food World, 9 (43), 40 - 43.

5. Edward M. Fox et. al. (2017), "Editorial: Microbial Food Safety along the Dairy Chain", Frontiers in Microbiology, (8), 1612.

6. Jin-Qiang Chen et. al. (2017), "PCR-based methodologies for detection and characterization of Listeria monocytogenes and Listeria ivanovii in foods and environmental sources", Food Science and Human Wellness, (6), 39 - 59.

7. Konstantia Halatsi et. Al, "PCR detection of Salmonella spp. using primers targeting the quorum sensing gene sdiA", FEMS Microbiol Lett 259 (2006), 201 - 207.

8. Joseph Odumeru. (2002), "Current Microbial Concerns in the Dairy Industry", Food Safety magazine.

9. Odd G. Brakstad et. al. (1992), "Detection of Staphylococcus aureus by Polymerase Chain Reaction Amplification of the nuc Gene", Journal of Clinical Microbiology, 7 (30), 1654 $-1660$.

10. Thúy An (2017). Hậu Giang: Trẻ ngộ độc do uống sữa có vi khuẩn Staphylococcus aureus. Quân đội Nhân dân online 06/11/2017 
11. Minh Nhật (2018). Cảnh báo về "thủ phạm” gây ra các vụ ngộ độc tập thể. daibieunhandan.vn online 16/12/2018

12. Yi Wang et. al. (2014), "Rapid and sensitive detection of Listeria monocytogenes by cross-priming amplification of lmo0733 gene", FEMS Microbiol Lett, 361, 43 - 51.

13. Eliezer Avila Gandra et. al. (2016), "Detection by multiplex PCR of Staphylococcus aureus, S. intermedius and S. hyicus in artifcially contaminated milk", Ciência Rural, Santa Maria, v.46, n.8, 1418-1423

14. KLM Moganedi et. al. (2007), "Optimisation of the PCR-invA primers for the detection of Salmonella in drinking and surface waters following a pre-cultivation step", Water $S A$, Vol. 33 No. 2.

15. M. Radhika et. al., "A novel multiplex PCR for the simultaneous detection of Salmonella enterica and Shigella species", Journal of Microbiology Online, ISSN 1678 - 4405

16. Kumar S., Balakrishna K. \& Batra H. (2006), "Detection of Salmonella enterica serovar Typhi (S. Typhi) by selective amplification of invA, viaB, fliC- $\mathrm{d}$ and prt genes by poly merase chain reaction in mutiplex format", Letters in Applied Microbiology, 2 (42), 149 - 154.

\section{LÒ̇I CẢM ONN}

Đề tài được tài trợ chính từ quỹ học bổng cho cựu nghiên cứu viên của tổ chức JICAKIRIN, Nhật Bản và Công ty Kirin, Nhật Bản.

Nhóm tác giả xin chân thành cảm ơn sâu sắc đến Tiến sĩ, Bác sĩ Vũ Thu Hằng, Đại học Y Thái Nguyên đã tặng chủng chuẩn Staphylococcus aureus và E. coli shigella; Bác sĩ Nguyễn Thái Sơn, Bệnh viện Quân Y 103 đã để lại cho chúng tôi chủng chuẩn Listeria monocytogenes; Thạc sĩ Lê Đình Duẩn, Công ty $\mathrm{CP}$ Công nghệ vi sinh và môi trường đã tặng chủng chuẩn Salmonella spp. và Vibrio cholera $O 1$ cho nghiên cứu; Tiến sĩ Nguyễn Phương Nhuệ, Viện Công nghệ Sinh học, Viện Hàn lâm Khoa học và Công nghệ Việt Nam đã giúp trong việc thu thập các mẫu sữa tươi tại các hộ cá thể tại hai xã Dương Hà và Phù Đổng, Gia Lâm, Hà Nội.

\section{Summary}

ASSESSMENT OF LISTERIA MONOCYTOGENES, STAPHYLOCOCCUS AUREUS AND SALMONELLA SPP. CONTAMINATION IN DAIRY SAMPLES COLLECTED IN GIA LAM AND BA VI, HANOI EARLY 2019

\section{Nguyen Thi Minh Huyen', Tran Thi Hoa', Ninh Thi Tuyet Lan', Tran Thi Hien ${ }^{2}$}

${ }^{1}$ Institute of Biotechnology, Vietnam Academy of Science and Technology

${ }^{2}$ Falcuty of Biology, VNU University of Science, National University, Hanoi Vietnam

Milk and dairy products from dairy farms around Hanoi greatly contribute to the consumed milk quantity in Hanoi. The use of fresh milk or pasteurized milk becomes more and more popular in the daily life of local people. Milk and dairy products were widely sold in numerous stores, particularly in Xuan Mai, Ba Vi, Phu Dong and Gia Lam. However, there have not yet been any studies to assess the pathogenic bacterial contamination of these products. In our study, 49 samples including 23 raw milk samples, 12 pasteurized milk samples, and 14 yogurt samples were collected in order to examine the presence of food-born pathogenic bacteria such as Listeria monocytogenes, Staphylococcus aureus, Salmonella spp. using PCR method. This fast and accurate method works based on the specific amplification of tested bacterial DNA. The results showed that one of the samples may contain Staphylococcus aureus while another may be contaminated with Listeria monocytogenes. None of the samples was contaminated with Salmonella spp. The results were confirmed by gene sequencing.

Keywords: Bacteria, food-poisoning, milk, bacterial contamination, Hanoi. 